1 Instituto René Rachou (IRR) - Fiocruz Minas

- Belo Horizonte (MG),

Brasil.

marcela_lima5@hotmail.

com

2 Universidade Federal de Ouro Preto (Ufop) - Ouro Preto (MG), Brasil.

\section{Território e desterritorialização: 0 sofrimento social por desastre ambiental decorrente do rompimento de barragens de mineração}

\author{
Territory and deterritorialization: the social suffering by \\ environmental disaster resulting from the breaking of mining dams
}

Marcela Alves de Lima Santos', Núncio Antônio Araújo Sol22, Celina Maria Modena'

DOI: 10.1590/0103-11042020E218

RESUMO Em Mariana, estado de Minas Gerais, após o Rompimento da Barragem de Fundão, famílias passaram por processo de desterritorialização, em que foram deslocadas da área rural para a área urbana. Assim, o objetivo do estudo foi compreender o processo de desterritorialização nesse contexto, as implicações da perda desse locus social para a vida dos atingidos e para a construção de respostas e políticas públicas de saúde. Foi realizada pesquisa qualitativa no período de 2016 a 2018 no município de Mariana, utilizando as técnicas de observação participante e entrevistas com pessoas atingidas. As entrevistas foram analisadas a partir da Análise de Conteúdo, e a discussão foi orientada pelo referencial teórico dos conceitos de território, desterritorialização e sofrimento social. Na observação e nos relatos dos participantes, é marcante a relação simbólica com seu lugar de origem, traduzidos na forma de vínculos e pertencimento. As perdas, em suas diferentes dimensões, impactam a vida desde o luto até o sofrimento social. Até o reassentamento, é necessário que as interpretações desse novo viver não sejam patologizadas para que as pessoas consigam estar conscientes desse processo e serem protagonistas das escolhas.

PALAVRAS-CHAVE Saúde pública. Desastres. Território sociocultural.

\begin{abstract}
In Mariana, state of Minas Gerais, after the Fundão Dam rupture, families went through a process of deterritorialization, in which they were moved from rural to urban areas. Thus, the aim of the study was to understand the process of deterritorialization in this context, the implications of the loss of this social locus for the lives of those affected and for the construction of public health responses and policies. A qualitative research was conducted from 2016 to 2018 in the city of Mariana, using participant observation techniques and interviews with affected people. The interviews were analyzed based on Content Analysis and the discussion was guided by the theoretical framework of the concepts of territory, deterritorialization, and social suffering. In the observation and reports of the participants, the symbolic relationship with their place of origin is remarkable, translated in the form of bonds and belonging. Losses, in their different dimensions, impact life from grief to social suffering. Until the resettlement is achieved, it is necessary that the interpretations of this new living are not pathologized so that people can be aware of this process and be the protagonists of their choices.
\end{abstract}

KEYWORDS Public health. Disasters. Sociocultural territory. 


\section{Introdução}

O estado de Minas Gerais, marcado historicamente pelo processo de desenvolvimento da mineração, transformou-se em cenário de rompimento de algumas barragens nos últimos anos. Já existiam episódios anteriores, como nos municípios de Itabirito no ano de 1986 e Cataguases no ano de 2003². Apesar desses fatos anteriores, são os desastres do Rompimento da Barragem de Fundão, de responsabilidade da empresa Samarco Mineração S.A. e de suas mantenedoras Vale S.A. e BHP Billiton, no município de Mariana, em novembro de 2015; e o Rompimento da Barragem I da Mina do Córrego do Feijão, pertencente à Vale S.A., no município de Brumadinho, em janeiro de 2019, que trazem visibilidade para o tema e para os diferentes tipos de danos e sofrimentos causados à população atingida. Cabe esclarecer que o conceito de desastre está relacionado com uma grave interrupção do funcionamento de uma comunidade ou sociedade, que causa grandes perdas e impactos e que excedem a capacidade da comunidade ou sociedade afetada de lidar com a situação mediante recursos próprios². Depois de Brumadinho, outros municípios como Barão de Cocais e Nova Lima (Macacos) passaram a conviver com o risco do rompimento de barragens, até então silenciado.

Em Mariana, cerca de 300 famílias foram deslocadas da área rural, principalmente das comunidades de Bento Rodrigues e Paracatu de Baixo, para a área urbana ${ }^{3}$. Em 2019, o mesmo processo ocorreu em Brumadinho, guardadas as suas diferenças e proporções. Diante do risco de rompimento de novas barragens, outras comunidades no estado passaram pela situação de serem retiradas de forma abrupta do local onde viviam 4 , deixando bens materiais, histórias, relações sociais e culturais para trás.

Entre as vivências em comum, essas comunidades de diferentes municípios trazem o fato de passar por um processo de desterritorialização e a obrigação de viver em outro lugar.
Como conceituado por Deleuze ${ }^{5(4)}$,

[...] não há território sem um vetor de saída do território e não há saída do território, ou seja, desterritorialização, sem, ao mesmo tempo, um esforço para se reterritorializar em outra parte.

O território é compreendido não simplesmente como um espaço geográfico, mas como também possuidor de um valor

[...] existencial: ele circunscreve, para cada um, o campo do familiar e do vinculante, marca as distâncias em relação a outrem e protege do caos. O investimento íntimo do espaço e do tempo implica essa delimitação, inseparavelmente material [...] e afetiva $\mathbf{6}^{\mathbf{( 2 3 )} \text {. }}$

O contexto de rompimento de barragens é mais um exemplo de situação de injustiça socioambiental, em que, diante da exposição a danos ambientais do desenvolvimento, ocorre um deslocamento de grupos sociais de forma abrupta e violenta7. Essa condição torna-se fonte de sofrimento para esses grupos que têm os seus modos de vida completamente alterados.

Nesse cenário, encontra-se um sofrimento de origem social ${ }^{8} \mathrm{em}$ indivíduos que têm sua realidade alterada e são colocadas em situação de privação. Freitas e colaboradores apontam a importância de compreender as consequências desses desastres para além do quantitativo de óbitos e danos à saúde imediatos, mas também na identificação de novos problemas e necessidades de saúde ao longo do tempo? Assim, é importante entender essa condição de deslocamento e perda territorial e como as pessoas são afetadas nesse processo para que as políticas de saúde sejam desenvolvidas em uma perspectiva ampliada.

Então, busca-se compreender o processo de desterritorialização no contexto de rompimento de barragens, as implicações da perda deste locus social para a vida das pessoas atingidas e para a construção de respostas e políticas públicas de saúde. 


\section{Material e métodos}

Foi realizada pesquisa qualitativa no município de Mariana (MG), entre os anos de 2016 e 2018, buscando compreender os impactos à saúde da população atingida pelo Rompimento da Barragem de Fundão ocorrido em 5 de novembro de 2015. Este estudo foi aprovado pelo Comitê de Ética em Pesquisa (CEP) do Instituto René Rachou (IRR) da Fundação Oswaldo Cruz (Fiocruz) conforme parecer $\mathrm{n}^{\mathrm{O}}$ 1.578.823/CAAE 53911916.0.0000.5091.

O município de Mariana está localizado na região central de Minas Gerais, a aproximadamente $110 \mathrm{Km}$ de Belo Horizonte. Também conhecida como a Primaz de Minas, foi a primeira capital do estado. Em 2019, a população estimada era de 60.724 pessoas distribuídas em uma extensão territorial de 1.194,208 Km² ${ }^{10}$. Trata-se de um município que apresenta forte dependência econômica da mineração e pouca diversificação econômica.

Os locais mais atingidos nesse desastre foram Bento Rodrigues e Paracatu de Baixo, subdistritos que foram soterrados pela lama. Bento Rodrigues era um lugar calmo, com matas, cachoeiras e igrejas e tinha população de aproximadamente 600 pessoas. Já em Paracatu de Baixo, também uma tranquila área rural, moravam cerca de 300 habitantes. Os dois subdistritos possuíam unidades de saúde e escolas, a Escola Municipal de Bento Rodrigues e a Escola Municipal de Paracatu de Baixo, que também foram destruídas nesse desastre"1.

As informações apresentadas neste artigo são parte desse processo de investigação e trazem elementos encontrados em campo. São apresentadas análises a partir de observação participante realizada pela primeira autora durante esses dois anos nos serviços de saúde e em espaços comunitários e coletivos construídos pelos atingidos nesse período. Com essa participação no campo, foi possível uma maior aproximação com a realidade e com as vivências cotidianas dessas pessoas. A observação participante também possibilita vincular fatos a suas representações por determinado grupo e permite ao pesquisador relativizar seu espaço social e aprender a se colocar no lugar do outro ${ }^{12}$.

Também foram realizadas entrevistas com pessoas atingidas no final de 2017 no município de Mariana, buscando compreender o significado das mudanças a partir do desastre, da desterritorialização e das suas consequências para o cotidiano e a saúde dessa população. As entrevistas foram gravadas e transcritas, após processo de consentimento livre e esclarecido. Antes da submissão, as participantes foram procuradas novamente para que autorizassem ou não a utilização da entrevista e a submissão do texto. Após reunião explicando os objetivos do estudo, foi entregue uma cópia da entrevista transcrita a elas, para que pudessem relembrar qual o conteúdo e retirar ou acrescentar algo. Após esse processo, os participantes legitimaram o uso e a divulgação neste artigo científico, resguardando o anonimato.

Para esta investigação, foi utilizada a técnica de análise de conteúdo ${ }^{13}$ buscando compreender os significados atribuídos pelas participantes a essa mudança de realidade de vida, à necessidade de adaptação a um novo território e às consequências do desastre para a condição de saúde da população atingida.

Assim, busca-se, a partir da experiência construída no município de Mariana e da análise das narrativas de pessoas atingidas, apontar os significados atribuídos ao fenômeno e contribuir com possibilidades de atuação para os novos cenários que se instalam no estado de Minas Gerais e que podem surgir também em outros locais.

\section{Resultados e discussão}

Em Mariana, após o desastre da Samarco, ocorreu uma mudança das famílias da área rural para a área urbana. Esse mesmo movimento também pode ser identificado em Brumadinho, após o Rompimento da Barragem I da Mina do Córrego do Feijão, e 
em comunidades como no município de Barão de Cocais com o risco de rompimento de mais uma barragem da Vale S.A. Em todos esses casos, foram indispensáveis intervenções de pessoas e instituições públicas e privadas em apoio a esses grupos.

Considerando a importância dos determinantes sociais e ambientais para o processo de saúde-doença, é possível observar que as consequências para a saúde ultrapassam o momento da ocorrência do desastre e do deslocamento das famílias. É necessário destacar que os desastres não se limitam ao evento catastrófico e podem ter a crise e o sofrimento social intensificados de acordo com as respostas institucionais que são dadas ${ }^{\mathbf{1 4}}$. Diante desse cenário, é preciso compreender os usos que são feitos nesses diferentes locais e como essas alterações ambientais trazem novas preocupações na área da saúde.

As mudanças impostas marcam a história dessas pessoas que são obrigadas a se adaptar a um novo lugar, com novos padrões e estilos de vida. A aproximação com a realidade dos atingidos mostra também que, com o rompimento da barragem e com a retirada abrupta de comunidades dos locais onde vivem, rompem-se laços e memórias.

Dessa forma, é necessário compreender o território para além de uma perspectiva de delimitação geográfica e estática, mas também permeada por todas as suas relações sociais, históricas e afetivas. Como definido por Guattari e Rolnik ${ }^{\mathbf{1 5}(323)}$ :

O território pode ser relativo tanto a um espaço vivido, quanto a um sistema percebido no seio do qual um sujeito de sente 'em casa'. O território é sinônimo de apropriação, de subjetivação fechada sobre si mesma. Ele é o conjunto de projetos e representações nos quais vai desembocar, pragmaticamente, toda uma série de comportamentos, de investimentos, nos tempos e nos espaços sociais, culturais, estéticos e cognitivos.

Milton Santos ${ }^{16}$ trouxe contribuições importantes para a Saúde Coletiva, apresentando o território como um objeto dinâmico, vivo, repleto de inter-relações, propondo o detalhamento das influências recíprocas do território com a sociedade, seu papel essencial sobre a vida do indivíduo e do corpo social.

Assim, compreende-se o território como espaço em que as histórias de vida acontecem e vão se modificando a partir dos processos políticos, econômicos e ambientais. Os rompimentos de barragens têm configurado cenários de rupturas nesses ciclos de vida, instalando a demanda da adaptação a um novo território, assim como da participação em outras instâncias comunitárias e de negociação política e contato com novas instituições.

Haesbaert ${ }^{17}$ apresenta uma concepção de território a partir de três vertentes: a jurídico-política, em que o território é entendido como um espaço no qual se exerce um determinado poder; a culturalista, que prioriza a compreensão da dimensão simbólico-cultural; e a econômica, que enfatiza a dimensão social das relações econômicas e o embate entre as classes sociais e na relação capital-trabalho.

Nos relatos dos atingidos, fica evidente a relação simbólica estabelecida com esse lugar, visto que grande parte das pessoas permaneceu nesse mesmo local desde o nascimento e ali escolheram constituir suas famílias. Observase o vínculo entre os moradores dos distritos de Bento Rodrigues e Paracatu de Baixo e como a vida foi construída de forma simples e tranquila, conforme exemplificado no trecho abaixo:

Quando a gente vivia lá? Todo mundo vivia num lugar tranquilo. Todo mundo tinha sua casinha. Quem não tinha, pagava seu aluguel, mas era gente dali mesmo. Se chegava um estranho para morar, todo mundo sabia que estava chegando e fazia as amizades. Era um lugar gostoso. Todo mundo conhecia todo mundo.

A insegurança aparece como um marco nesse novo território onde as relações de confiança são mais raras. Como apresentado na fala acima, nas pequenas áreas rurais, todos se conheciam; 
e a rede de suporte social era maior e mais fortalecida. Com o deslocamento para a área urbana e o distanciamento das moradias, há uma quebra em vínculos comunitários. Além disso, as comunidades passam a viver em um ambiente de maior exposição a vários tipos de violência. Dessa forma, essa população também passa por um processo de vulnerabilização ${ }^{6}$.

Nesse cenário, são encontradas perdas que nos remetem a um esperado processo de luto. No desastre em Mariana, ocorreram 19 mortes que sinalizam perdas expressivas para as famílias e comunidades. Porém, neste artigo, a discussão está voltada para o luto e o sofrimento de origem social e simbólica. Esse contexto traz relações de privações e perdas que podem ser observadas em várias dimensões. Na fala abaixo, é possível identificar o distanciamento e a separação que ultrapassam o limite espacial ou geográfico e determinam uma nova conformação de relações sociais.

Era uma comunidadezinha pequena. Então, cada um está para um lado, para um bairro. E o bairro se torna distante, é uma cidade pequena, mas se torna distante. É mãe aqui e filha para o lado. E aí, foi separado. Pessoas que a gente via todo dia, às vezes duas vezes no dia, e hoje fica até semana sem ver.

Assim como em outros processos migratórios em período de globalização, interesses econômicos e políticos são colocados acima dos direitos e necessidades da população ${ }^{7}$. Tratamos de pessoas que foram deslocadas de forma involuntária, excluídas de um lugar sem possibilidade de escolha. Diante dessa impossibilidade, inicia-se a trajetória de adaptação em um novo território. As pessoas atingidas passaram por um processo de reconhecimento da área urbana da cidade e pela necessidade de construção de outro formato de reorganização social.

Assim, encontramos uma população que passa por um processo de desterritorialização e que leva à necessidade de uma nova territorialização,
[...] 'reterritorialização', que leva ao tema polêmico da 'nova terra', sempre por vir e a ser construída, contra toda terra prometida ou ancestral, $[\ldots]]^{5(23)}$.

A partir da compreensão do território em sua dimensão cultural, a desterritorialização é vista a partir do processo de desenraizamento e enfraquecimento de identidades territoriais ${ }^{17}$. Acontece, assim, a construção de um processo de exclusão social e de perda de autonomia desses grupos sociais.

Ao pensar na retirada abrupta dessas pessoas, é possível relacionar algo que é colocado como um imperativo e que deve ser cumprido imediatamente. Nesse caso, trata-se da condição de deixar sua história e todos os seus bens materiais e imateriais para continuar uma vida. Nas entrevistas, os agradecimentos pela vida são constantes em falas de pessoas que vivenciaram de perto a sensação de morte: "Mas não foi nada fácil não. E hoje temos que agradecer a vida, da gente estar aqui. Mas não é fácil a gente viver num lugar que não é da gente".

Encontra-se a necessidade do sentimento de gratidão, mesmo com a dor que se faz presente. É como se não fosse permitido reclamar, externalizar ou dizer que não está bem, visto que se tem a possibilidade de estar vivo. A tristeza por ter perdido tudo e a não identificação com essa nova condição se misturam ao reconhecimento de que algo pior poderia ter ocorrido.

E aí a vida é outra, você já se deslocou, já passou por uma situação complicada. Perdeu tudo. Evem para um lugar que não é a sua casa. Eé um apartamento e é a adaptação ao lugar. Mas todo mundo agradece, ao mesmo tempo fala, agradeço a Deus por estar aqui.

A dialética entre a vida e a morte aparece de forma frequente no discurso das entrevistadas. Como foi dito no relato acima, a vida é outra; e, então, novas construções precisam ser feitas. Observa-se que, mesmo diante da concretude da vida que se apresenta, encontra-se a morte no 
plano social. A morte social revela um paradoxo sobre como o biológico e o social se fundam, ocorre quando determinadas perdas de funções acarretam interdições, no sentido de que há um rompimento dos papéis desempenhados pelo indivíduo num determinado grupo ${ }^{18}$.

Santos ${ }^{19(16)}$ aponta que é o uso do território que o caracteriza como objeto de análise social e considera que "o território usado são objetos e ações, sinônimo de espaço humano, espaço habitado". A partir do contato com as pessoas atingidas, é possível perceber como essa relação com o território é construída e como as pessoas buscam se encontrar nesse novo lugar onde a relação de pertencimento não existe. Nas falas, identificamos que as pessoas se reconhecem como inquilinas na área urbana de Mariana que, até então, era um território utilizado apenas para resolução de problemas, ir a uma consulta de saúde ou ao banco.

Como a casa de alguém. Por exemplo, eu me sinto assim, é a casa de alguém e a qualquer hora o dono chega. Eu vivo assim lá. O ser meu é diferente. E éo que todo mundo espera, está todo mundo ansioso porque tem a data prevista, mas todo mundo fica assim, será que vai realmente sair nesta data?

Logo após o Rompimento da Barragem de Fundão, as famílias atingidas foram levadas para o Ginásio Poliesportivo em Mariana e, no dia seguinte, para hotéis e pousadas no município ${ }^{2}$. No mês seguinte ao desastre, começaram a ser alojadas em casas alugadas ${ }^{\mathbf{2 0}}$. Mesmo não estando em situação de abrigo coletivo ou morando em casas de familiares ou amigos, as pessoas relatam se sentir na condição de inquilinos. Dessa forma, nota-se como o espaço físico por si só não constitui a identidade e o pertencimento àquele lugar e como o território se constrói a partir de elementos e sentimentos diversos daqueles que o constituem e determinam o seu uso. Como conceituado por Milton Santos ${ }^{21(96)}$,

O território não é apenas o resultado da superposição de um conjunto de sistemas naturais e um conjunto de sistemas de coisas criadas pelo homem. O território é o chão e mais a população, isto é, uma identidade, o fato e o sentimento de pertencer àquilo que nos pertence. O território é a base do trabalho, da residência, das trocas materiais e espirituais e da vida, sobre os quais ele influi. Quando se fala em território deve-se, pois, de logo, entender que se está falando em território usado, utilizado por uma dada população.

É possível identificar, também, que essas pessoas não apresentavam laços afetivos nesse novo lugar. Assim, podemos sinalizar um não território, visto que o território perde o sentido de aglutinador de identidades, e as pessoas participam menos de referências espaciais e identitárias ${ }^{17}$.

Entre o tempo de ocorrência do desastre e o final do reassentamento, fica a espera por um novo lugar. Até o final da escrita deste artigo, não havia uma única casa construída, ou seja, são aproximadamente quatro anos de espera. Os relatos exemplificam a trajetória nesse reconhecimento, em que, entre um espaço físico e outro, as pessoas vão buscando ressignificação dos territórios e memórias.

Falam mais os homens: ah, eu não tenho o que fazer. Rodo aqui e rodo ali, vou num parque e no outro. E aí, vou sair e sento ali com um colega, não sei quem. E então, às vezes tem alguns que já tem os pontos, tanto Bento como Paracatu como as outras comunidades, e assim vai passando, como se diz, até acabar esta ansiedade.

Na dinâmica de adaptação a esse novo território, muitas pessoas perderam atividades de trabalho, lazer e subsistência. Como destacado na fala acima, é comum encontrar homens queixando-se da ociosidade. A partir disso, alguns pontos da cidade, como o Centro de Convenções, foram se destacando como possibilidade de promoção de encontros para essas comunidades. Junto com as caminhadas pela cidade e as conversas, vê-se o tempo passar, e espera-se que chegue logo o tão esperado 
momento de um novo território, por eles chamado "Novo Bento" ou "Nova Paracatu".

O sentimento relatado é de "ansiedade", outra forma de apresentação do sofrimento. Nesse ponto, é importante observar como o sintoma psicológico aparece e precisa ser bem interpretado e dimensionado para evitar atuações no campo da saúde que tenham um foco individualizante. Como chamam a atenção Weintraub e colaboradoras ${ }^{22}$, a saúde mental precisa ser pensada de "forma múltipla, analisando-se os distintos significados atribuídos de forma singular e coletiva ao evento experienciado".

A ansiedade é relatada dentro de um processo de perda e de espera por algo que se deseja muito, mas em que não há segurança de que realmente irá se concretizar.

Dá para levar até chegar lá, mas não sei até quando a gente vai aguentar. E aí outros falam: será que eu aguento chegar até lá, na data prevista de voltar? E outros tem aquele medo, será que vai mesmo sair nesta data as construções. E algumas pessoas também já se preocupam, como vai ser a nossa adaptação lá neste local. Apesar de que tem uma diferença, é a minha casa. Mas a adaptação do lugar, como vai ser?

Existe uma condição social nesse contexto que é geradora de sofrimento. Grande parte dos processos de desterritorialização está relacionada com aspectos políticos e socioeconômicos. No caso do rompimento de barragens, existem interesses e relações de poder que sobressaem aos desejos e vontades de determinadas populações, colocando-as em condição de vulnerabilidade. Ao sair do território onde construíram suas memórias e histórias, passam a uma condição de pouca independência e autonomia e de ruptura das suas redes sociais.

Além disso, passaram pela perda de algumas funções, das referências e dos papéis sociais. Quem gostava de plantar não possuía mais o quintal de casa ou o lote vago na vizinhança. Aqueles que se identificavam com a criação de animais não tinham animais nem espaço.
Os que retiravam grande parte da alimentação do próprio terreno precisaram aprender a ir ao supermercado e comprar produtos que apresentam outra qualidade. Existem relatos de idosos que nunca tinham precisado comprar um ovo porque sempre criaram galinhas em casa.

A edição 40, de julho de 2019, do 'Jornal A Sirene'23, um jornal feito para dar voz aos atingidos, também mostra como tradições foram perdidas e como as comunidades se organizam para resistir e sustentar alguns desses costumes. Nessa edição, são apresentados alguns relatos de moradores sobre a festa de Santo Antônio, tradicional celebração do padroeiro de Paracatu que eles lutam para que não fique apenas na memória. A fala da moradora no trecho abaixo exemplifica algumas dessas mudanças para a comunidade.

Hoje chegamos lá e é tudo rápido, tem de ser tudo cronometrado. Quando a gente morava lá, era muito diferente porque nós arrumávamos todo o espaço. As pessoas que dançavam quadrilha iam todas caracterizadas. Era muito bonito e gostoso. Tinha fogueira, show, barraquinhas, a rua era muita enfeitada. Agora, não temos mais esse tempo de ficar organizando, de convidar muitas pessoas ${ }^{\mathbf{2 3}(15)}$.

Assim, novas marcas e modos de vida são colocados para essas populações que se tornam vulnerabilizadas e inseridas em um cenário de maior desigualdade social. Entende-se, aqui, a vulnerabilização como um processo, que inclui a historicidade dos fatos e os direitos que foram retirados desses grupos sociais ${ }^{24}$.

Dessa forma, é preciso considerar que existe uma população atingida que é colocada em uma condição de iniquidade em saúde. Então, é preciso estar atento aos fatores sociais em um contexto de tantas perdas para que as questões de saúde não sejam reduzidas a diagnósticos e prescrições, culminando em processos de patologização e medicalização ${ }^{20}$.

Entendendo que a noção de trauma ainda aparece como um operador do cuidado em saúde mental produzido em situação de 
desastres ${ }^{22}$, pode haver uma tendência dos profissionais de saúde (médicos em especial) em reduzir o sofrimento dessas pessoas a um número da Classificação Internacional de Doenças (CID), passível assim de ser resolvida somente com o uso de um antidepressivo ou modulador de humor. Nesse contexto, são comuns diagnósticos de transtorno de estresse pós-traumático e depressão mal elaborados, em que se desconsidera o contexto do adoecimento. Além disso, a medicalização, compreendida como a prescrição com a intenção de suprimir sintomas, interfere na capacidade dos atingidos pelo desastre de compreender toda a motivação e as causas do seu sofrimento, dificultando a participação em instâncias de luta por direitos e o processo de reterritorialização.

Em meio à ansiedade, ao medo e ao estranhamento, os sonhos vão sendo construídos. A vontade de voltar a ter o seu lugar persiste. Ao mesmo tempo, as entrevistas mostram que os atingidos também já compreendem que se trata de um novo tempo e de um novo lugar. Quando entrevistada sobre como ela gostaria que fosse o 'Novo Bento', a atingida responde:

Que as pessoas continuassem com as mesmas amizades, porque eu acho que isso vai mudar muito também. As cabeças não vão ser as mesmas que vão voltar, as pessoas sim, mas as cabeças não. E espero que todo mundo vai ter aquela coisa gostosa de viver lá, apesar de ser um novo lugar. Mas a gente espera que seja tudo tranquilo e pensa mais nesta questão da adaptação. Até falar assim, esta é a minha casa. Esta é a minha rua. Este é o nosso Bento. E assim também são as outras comunidades. Mas vai ter um impacto também no início. É tudo novo de novo.

É possível perceber nas narrativas que, enquanto o reassentamento não acontece, é preciso continuar a vida. Apesar de alguns projetos parados e da insegurança em relação ao futuro, outras relações e vínculos também foram construídos na área urbana de Mariana. Então, mais uma vez, encontra-se um cenário futuro de desterritorialização e reterritorialização. Como apontado pela atingida, "é tudo novo de novo". E, mais uma vez, com essa mudança, novas análises e interpretações precisam ser realizadas para compreensão dos determinantes sociais envolvidos e suas consequências para o planejamento e construção das ações em saúde.

\section{Considerações finais}

A desterritorialização tem sido consequência frequente dentro dos desastres envolvendo rompimento de barragens em Minas Gerais. Com o deslocamento forçado do local onde vivem, as pessoas perdem suas memórias, identificações e vínculos sociais e comunitários. Assim, além dos óbitos registrados nesses desastres, existe uma morte social a partir da perda de elementos e função constituidores da história de vida dessas pessoas.

Diante desse contexto, mudam também as necessidades de vida. As perdas, em suas diferentes dimensões, impactam a vida dos atingidos e modificam a existência e/ou a direção dos seus projetos. Dessa forma, trazem consequências para a condição de saúde deles. Por isso, é importante que essa compreensão ampliada dos determinantes sociais envolvidos seja realizada para o desenvolvimento de ações de atenção à saúde compatíveis com as reais demandas da população atingida, seja no nível assistencial ou de vigilância.

Nesse momento em que o reassentamento ainda é esperado com tanta expectativa, é necessário que as interpretações desse novo viver não sejam patologizadas para que as pessoas consigam estar conscientes desse processo e para que sejam, também, protagonistas das escolhas nos espaços de participação social.

\section{Colaboradores}

Santos MAL (0000-0002-7579-8067)*, Sol NAA (0000-0002-7799-0458)* e Modena CM (0000-0001-5035-3427)* contribuíram igualmente na elaboração do manuscrito.
*Orcid (Open Researcher and Contributor ID). 


\section{Referências}

1. Lagoa T. Pelo menos 94 pessoas morreram após rompimento de barragens em MG [internet]. Jornal O Tempo. 2019 jan 28. [acesso em 2019 jul 30]. Disponível em: https://www.otempo.com.br/cidades/pelo-menos-94-pessoas-morreram-apos-rompimento-de-barragens-em-mg-1.2128094.

2. United Nations International Strategy for Disaster Reduction. Terminology on Disaster Risk Reduction [internet]. Geneva; Switzerland: UNISDR; 2009. [acesso em 2019 set 18] Disponível em: https://www.unisdr. org/files/7817_UNISDRTerminologyEnglish.pdf.

3. Santos MAL, Rossi SR. A construção do cuidado psicossocial aos atingidos do desastre de Mariana (MG): um relato de experiência. In: Sant'anna Filho O, Lopes DC. O psicólogo na redução dos riscos de desastres: teoria e prática. São Paulo: Hogrefe Cetepp; 2017. p. 185-196.

4. Trajano H, Leocádio T. Barragens da Vale em Macacos e Ouro Preto entram em alerta máximo para risco de rompimento [internet]. G1. 2019 mar 27. [acesso em 2019 jul 30]. Disponível em: https://gl.globo.com/ $\mathrm{mg} /$ minas-gerais/noticia/2019/03/27/barragem-da-vale-em-macacos-entra-em-alerta-maximo-para-risco-de-rompimento-e-sirenes-serao-acionadas. ghtml.

5. Deleuze G. O abecedário de Gilles Deleuze [internet]. 1989. [acesso em 2019 jul 30]. Disponível em: http://stoa.usp.br/prodsubjeduc/files/262/1015/ Abecedario+G.+Deleuze.pdf.

6. Zourabichvili F. O Vocabulário de Deleuze. Rio de Janeiro: IFCH-Unicamp; 2004.

7. Porto MFS. Complexidade, processos de vulnerabilização e justiça ambiental: um ensaio de epistemologia política. Rev Crítica Ciênc Sociais. 2011; (93):31-58.

8. Werlang R, Mendes JMR. Sofrimento social. Serviço Soc. 2013; (116):743-68.

9. Freitas CM, Barcellos C, Asmus CIRF, et al. Da Sa- marco em Mariana à Vale em Brumadinho: desastres em barragens de mineração e Saúde Coletiva. Cad. Saúde Pública. 2019; 35(5):e00052519.

10. Instituto Brasileiro de Geografia e Estatística. Panorama Mariana [internet]. 2019. [acesso em 2019 set 20]. Disponível em: https://cidades.ibge.gov.br/brasil/mg/mariana/panorama.

11. Graça A, Camargo COSFA, Santos J. A vida antes da tragédia. In: Caldas G, organizador. Vozes e silenciamentos em Mariana: crime ou desastre ambiental? 2. ed. Campinas: BCCL; Unicamp; 2017.

12. Minayo MCS. O desafio do conhecimento: pesquisa qualitativa em saúde. 14. ed. São Paulo: Hucitec; 2014.

13. Bardin L. Análise de Conteúdo. São Paulo: Edições $70 ; 2008$.

14. Zhouri A, Valencio N, Oliveira R, et al. O desastre da Samarco e a política das afetações: classificações e ações que produzem o sofrimento social. Ciênc. Cultura. 2016; 68(3):36-40.

15. Guattari F, Rolnik S. Micropolítica: cartografias do desejo. Petrópolis: Vozes; 1986.

16. Lima EFMA, Yasui S. Territórios e sentidos: espaço, cultura, subjetividade e cuidado na atenção psicossocial. Saúde debate. 2014; 38(102):593-606.

17. Haesbaert R. Da desterritorialização à multiterritorialidade. Boletim Gaúcho Geog. 2003; (29):11-24.

18. Aredes J. Um morrer em vida: a morte social na esfera da saúde [internet]. [acesso em 2019 ago 28]. Disponível em: http://observatoriodadiversidade.org.br/ site/um-morrer-em-vida-a-morte-social-na-esfera-da-saude.

19. Santos M. O retorno do território. In: Santos M, Souza MAA, Silveira ML, organizadores. Território - globalização e fragmentação. 4. ed. São Paulo: Hucitec; Anpur; 1998. p. 15-20. 
20. Santos MAL. Eu quero minha liberdade de volta! Saúde Mental e Atenção Psicossocial junto aos Adolescentes Atingidos pelo Rompimento da Barragem de Fundão. [dissertação]. Belo Horizonte: Instituto René Rachou. Belo Horizonte; 2018. 90 p.

21. Santos M. Por uma outra globalização - do pensamento único à consciência universal. 5. ed. Rio de Janeiro: Record; 2001.

22. Weintraub ACAM, Noal DS, Vicente LN. Atuação do psicólogo em situações de desastre: reflexões a partir da práxis. Interface (Botucatu). 2015 [acesso em 2020 jun 22]; 19(53):287-298. Disponível em: https://www.scielo.br/scielo.php?pid=S1414$-32832015000200287 \&$ script=sci_abstract\&tlng=pt.

23. Jornal A Sirene. Para não esquecer: Festas Interrompidas [internet]. 2019. [acesso em 2019 set 21]. Dis- ponível em: https://issuu.com/jornalasirene/docs/ julho_2019_issuu.

24. Acselrad H. Vulnerabilidade ambiental, processos e relações [internet]. In: II Encontro Nacional de Produtores e Usuários de Informações Sociais, Econômicas e Territoriais; 2006 Aug 24. Rio de Janeiro: ABIA/ IMS-Uerj; 2006. p. 1-5. [acesso em 2020 maio 6]. Disponível em: http://www.nuredam.com.br/files/divulgacao/artigos/Vulnerabilidade\%20Ambientais\%20 Proce\%20ssos\%20Rela\%E7\%F5es\%20Henri\%20 Acselrad.pdf.

Recebido em 29/09/2019

Aprovado em 04/02/2020

Conflito de interesses: inexistente

Suporte financeiro: não houve 